\title{
Reading Strategies Used by Senior High School Students to Comprehend English Texts
}

\author{
Zumrotul Fauziah \\ Pendidikan Bahasa dan Sastra \\ Universitas Negeri Surabaya \\ Surabaya, Indonesia \\ zumrotulfauziah@mhs.unesa.ac.id
}

\author{
Ahmad Munir \\ Pendidikan Bahasa dan Sastra \\ Universitas Negeri Surabaya \\ Surabaya, Indonesia \\ ahmadmunir@unesa.ac.id
}

\author{
Aswandi \\ Pendidikan Bahasa dan Sastra \\ Universitas Negeri Surabaya \\ Surabaya, Indonesia \\ aswandi@unesa.ac.id
}

\begin{abstract}
This survey study explored reading strategies employed by senior high school students in Bojonegoro-East Java, Indonesia. The study aimed to find out how often the students use of Global strategies, Problem-solving strategies, and Support strategies employment in comprehending English texts. It also investigated whether the students with different levels of reading proficiency applied similar or different reading strategies, and the extent of the use of reading strategies in helping the students in comprehending English texts. The data were collected by administering modified SORS (Survey of Reading Strategies) to 298 students at one of Islamic senior high school (Madrasah Aliyah) in Bojonegoro. The findings indicated that the senior high school students used Problem-solving strategies more frequently than Global strategies and Support strategies. The finding also revealed that there was difference in reading strategies applied by the students with different levels of reading proficiency. Moreover, the use of reading strategies was moderately correlated with the students' reading comprehension. It was suggested that English teachers motivate and train the students to use the reading strategies appropriately to enhance their reading comprehension. The teachers was also suggested to give reading strategy training for the poor readers so that they could have better reading comprehension.
\end{abstract}

Keywords: Reading strategies use; reading proficiency; reading comprehension

\section{INTRODUCTION}

In Indonesia, English is formally taught as a required course from seventh grade of junior high school until twelfth grade of senior high school. In these levels, the students deal with several genres of texts, such as descriptive, recount, narrative, analytical exposition text, etc. Therefore, it becomes something unavoidable for students to have sufficient proficiency needed for their study, especially reading proficiency. According to [1], reading skills are generally represented in four categories: word attack (decoding skill), comprehension skill, fluency skill, and critical reading skill. Among the four skills, comprehension skill seems to be the most important skill needed by the students in senior high school level. However, based on the researcher's experience in teaching English at senior high school level, most of the students tend to have low comprehension skill. Several aspects are assumed to be factors which affect the students' reading comprehension, such as lack of knowledge about English, low motivation in reading, and less awareness of reading strategies. Many studies have been conducted to measure the awareness of reading strategies. More specifically, the studies explore reading strategies use and other affecting factors, such as gender, field of study, and English learning experience [2] [3][4]. The studies show that the use of reading strategies is not affected by gender, field of study, and English learning experience. Therefore, it is important to investigate more deeply regarding the use of reading strategies and other factors which possibly affect the use of the reading strategies. Especially, the current study focused on the difference of reading strategies used by the students with different levels of reading proficiency. Further, the study sought to find out the extent of the use of reading strategies in helping the students to comprehend English texts. The recent study is different from the previous studies in some aspects: Firstly, this study was conducted in senior high school level. Secondly, this survey research focuses on the frequency of use of reading strategies, the selection of reading strategies based on students' reading proficiency, and students' perception of the extent of the reading strategy use in helping the students to comprehend English texts.

\section{THEORIES}

\section{A. The Concept of Reading}

Reading commonly defines as the activity to draw meaning from written materials. [5] suggest that reading is the 
combination of skills and strategies which involves cognitive process, the second language proficiency, and the ability to connect the text with the social context. According [6], reading is the interaction between reader and text. During the process of reading, the readers are not merely looking at the text and trying to find out the meaning of the text but they also connect the text to their previous knowledge. In addition, he suggests that reading involves the combination of automatic and conscious mental activity. To summarize, reading can be defined as activity to comprehend written materials which integrates both skills and strategies. Moreover, cognitive skill, knowledge about the language, and second language proficiency affect the process of reading.

\section{B. Reading Strategies}

[1] describes reading strategy as "any interactive process that has the goal of obtaining meaning from connected text, and reading skills operate within the context of such reading strategies". In addition, [7]defines a strategy as "an intentional plan that readers use to help themselves make sense of their reading. Strategies are flexible and can be adapted to meet the demands of the reading task.". In line with [7], [8] defines reading strategies as deliberate, cognitive steps that learners can take to assist in acquiring, storing, and retrieving new information and thus can be accessed for a conscious report" [8]. Furthermore, [9] describe reading strategies as: First, intentional, carefully planned techniques by which readers monitor or manage their reading. Second, actions and procedures that the readers use while working directly with a text. Third, basic support mechanisms intended to aid the readers in comprehending the text. They classify the reading strategies into three categories: Global Reading Strategies (GLOB), Problem-solving Strategies (PROB), and Support Strategies (SUP). In this study, the reading strategies refers to methods used by senior high school students to derive meaning from what is read. For example, taking notes, consulting dictionaries, etc. In other words, reading strategies are the way the readers interact or work with the texts. The strategies are well-planned and can be used interchangeably based on the reading task. Further, the reading strategies are employed while the readers work with the texts to help them monitor and manage their reading, so that they can achieve the reading purposes.

\section{Levels of Reading Proficiency and Reading Strategies}

Levels of Reading proficiency is the category of students' ability in comprehending English texts compared to other students. The students with different levels of reading proficiency may apply particular reading strategies differently. Good readers may use methods which different from the poor ones in deriving meaning from English texts they read. [10] suggests that "The stage(s) at which readers struggle may differ depending on the reader and text characteristics.". Good readers may meet problems to draw inferences of unfamiliar text if they lack of required knowledge about the language of the text (e.g.: technical terms, etc). However, poor readers will meet more problems not only the specific terms used in the text but also unfamiliar vocabularies used in the text which make the comprehension process more challenging. According to [7], "Good readers use lots of strategies to help themselves make sense of text.". To give an illustration, Tovani compares the good readers and the poor readers, when good readers read text which seems difficult for them, they will reread the text or read the text slowly. In the opposite, poor readers do different thing when the text seems difficult: "listening to Walkman while reading, fall asleep, daydreaming, etc." [7].

\section{Review of Previous Studies on Reading Strategies}

Study on language learning strategies has increased, particularly on reading strategies. [11] conducted a research on the selection of reading strategies among gender of EFL college students. The result revealed that there were differences on the selection of reading strategies between male and female students, but the difference was not significant. On the other hand, [4] conducted study on the relationship between reading strategy use and text type, and the relationship of reading strategies and reading proficiency. The study showed readers use reading strategies more frequently when reading the authentic expository/technical text than when reading the authentic narrative text. Furthermore, the study also revealed that high proficiency students use reading strategies more frequently than the low proficiency students. The finding favored other studies on the relationship between reading strategies and reading proficiencies [12][13][14][15] . Thus, text type and the students' reading proficiency affected the use of reading strategies.

\section{METHOD}

This section presents the research design, research setting, the participant, data and source of data, data collection technique, and data analysis.

\section{A. Research Design}

This study used quantitative study as the research design. A survey was conducted to collect the data needed for the study. According to [16], survey research has three characteristics: "1) Information is collected from a group of people to describe some aspects of characteristics, 2) The main way to collect the information is through asking questions, 3) Information is collected from a sample rather than from every member of the population." [16]. Furthermore, [17] suggests that survey research is an appropriate tool to measure people's preferences, attitudes, behavior, and other factual information in large population [17]. Therefore, by conducting the survey, the researcher was able to find out the characteristics of senior high students in the use of reading strategies.

\section{B. Research Setting}

This study was conducted at Madrasah Aliyah (Islamic senior high school) in Bojonegoro, East Java. There were 52 Madrasah Aliyah in Bojonegoro, with total population of 9.387 students. From the population, the researcher selected one school as a sample. The school was choosen since it is administratively accessible for the researcher. There were 307 students at that school i.e. 107 students at tenth grade (three classes), 118 students at eleventh grade (four classes), and 82 students at twelfth grade (three classes). Based on the 
researcher's experience in teaching English in that school, the students still found difficulties in understanding English texts during the reading class. It was proved by the score of reading test in the First Final Semester Test which described that most of the students had low comprehension skill. The researcher assumed that the students' low comprehension skills might be caused by less awareness of reading strategies use. Therefore, the researcher is interested in investigating the reading strategies employed by the students in that school.

\section{Research Samples}

The samples of this study were the students at one of Madrasah Aliyah (Islamic senior high school) in Bojonegoro which consisted of 307 students. However, nine students did not respond to the questionnaire. Therefore, the total number of participants of this study was 298 who come from tenth to twelfth grade. In this study, the researcher categorized the students' level of reading proficiency based on the score of reading comprehension. To get the reading score, the researcher asked for the score of reading in First Final Semester Test from the English teachers to determine the level of reading proficiency. The scores showed that the mean score of overall students from tenth grade until twelfth grade was 41.7. The maximum score was 78 , and the minimum score was 14. Based on these scores, the students were categorized into three levels of reading proficiency, namely intermediate readers (i.e. score of 60-79), poor readers (i.e. score of 40-59), and very poor readers (i.e. score of $\leq 39$ ). The group of intermediate readers consists of 27 students, the group of poor readers consists of 145 students, and the group of very poor readers consists of 126 students.

\section{Data and Source of Data}

The data of this research was quantitative data which were obtained from questionnaire. The data contained information about how often the students used the reading strategies to comprehend English text and the perception of usefulness of reading strategies employment. The questionnaire was the only data source of this research since the participant of this survey research was a large number of students. Data from the questionnaire was analyzed statistically to describe the characteristic of the students in employing the reading strategies to comprehend English texts.

\section{E. Data Collection Technique}

To collect the data, the researcher used modified SORS (Survey of Reading Strategy) questionnaire proposed by [9] The original SORS consisted of 5 scales i.e. ' 1 ' means that 'I never or almost never do this', ' 2 ' means that 'I do this only occasionally', ' 3 ' means that 'I sometimes do this', '4' means that 'I usually do this', '5' means that 'I always or almost always do this'. However, in the modified SORS, the scales were simplified into four and a column contained the perception of usefulness (with four scales) was also added to meet the research demands. The questionnaire was Likert scale questionnaire which was very useful to build degree of sensitivity and variation of response in form of number [18] (p. 325). The questionnaire was translated into Indonesian language so that the students did not get difficulties in filling the questionnaire. It was administered to all participants of the research to find out the frequency of use of the reading strategies and the students' perception of the usefulness of reading strategies to comprehend English texts.

Specifically, the questionnaire consisted of thirty items of reading strategies which were categorized into Global strategies, Problem-solving strategies, and Support strategies. Items 1- 13 belong to Global strategies, items 14- 21 belong to problem-solving strategies, and items 22- 30 belong to Support strategies. Each items of reading strategies followed by two columns i.e. the column of frequency of use and the column of perceptions of usefulness. The frequency of use of reading strategies are presented in column "I do this..." with four possible responses i.e. "1" means "I never do this", "2" means "I sometimes do this", " 3 " means "I often do this", and "4" means "I always do this". Similarly, the students" perceptions of usefulness are presented in column "I think it is ..." with four possible responses as well i.e. " 1 " means "It is not helpful for my understanding", " 2 " means "It is a bit helpful for my understanding", " 3 " means " It is quite helpful for my understanding, and " 4 " means "It is very helpful for my understanding".

\section{F. Data Analysis}

This study used Statistical Package of the Social Science (SPSS) version 20 to analyze the data, especially descriptive statistic, Analysis of Variance (ANOVA), and regression analysis. More specifically, the statistical analysis used in this research was explained in detail as follows.

Research Question 1: How often the students use Global strategies, Problem solving strategies and Support strategies?

The first research question was asking about the frequency of reading strategies (Global, problem-solving, and support strategies) used by the students. The measure of frequency allowed the researcher to understand which strategies were most frequently used by the students and which were less frequently used by them. Descriptive statistics analysis was conducted to measure the frequency of reading strategies used by the students.

Research question 2: Do the students with different level of reading proficiency use the similar or different reading strategies?

To answer the second research questions, the researcher used one- way Analysis of Variance (ANOVA) since there were more than two groups being compared. In this analysis, there was one dependent variable, which was the use of reading strategies, and one independent variable, which was group of different levels of reading proficiency. In this study, there were three groups of different level of reading proficiency, namely intermediate readers, poor readers, and very poor readers. Therefore, the researcher used one-way ANOVA to find out the difference of the use of reading strategies among the three groups.

Research question 3: to what extent does the use of reading strategies help the students to comprehend English texts? 
The third research question was investigating the usefulness of reading strategies toward the reading comprehension based on the students' perceptions. More specifically, it sought to understand whether the reading strategies used by the students had a great or small contribution towards their reading comprehension. Therefore, a regression analysis was used by the researcher to answer the research question. The regression analysis was used to find out how much the frequency of use of reading strategies contributes to students' perceptions of the usefulness of reading strategies to comprehend English texts. To get more evidence of the extent of using reading strategies to help the students in comprehending English texts, another regression analysis was conducted in two variables: the scores of frequency of use of reading strategies as the independent variable and the students' reading scores as the dependent variable.

\section{RESULT AND DISCUSSION}

This section elaborates the result of data analysis and the finding of the research. The elaboration is presented in three sections, namely reading strategies used by senior high school students, the difference of reading strategies used by students with different levels of reading proficiency, and the extent to which reading strategies help the students in comprehending English texts.

\section{A. Reading Strategies Used by Senior High School Students}

A descriptive statistics analysis was applied to answer the first research question, that is the frequency of use of Global strategies, Problem-solving strategies, and Support strategies. The frequency of each reading strategy was described by the mean score. [9] interpreted that mean of 3.5 or higher indicated high usage, mean of 2.5 to 3.4 showed moderate usage, and mean of 2.4 or lower described low usage. These levels of interpretation were based on [19] average for measuring language learning strategies in general. Based on the data from the questionnaire, the average score of the overall use of reading strategies was 2.55 which indicated the medium usage of the reading strategies. The frequency of use of each reading strategy category was summarized in Table 1 below.

TABLE I. TABLE 1. THE RANK OF FREQUENCY OF USE OF EACH STRATEGY CATEGORY $(\mathrm{N}=298)$

\begin{tabular}{|l|l|l|l|}
\hline No. & \multicolumn{1}{|c|}{ Categories of Strategy } & \multicolumn{1}{c|}{ Mean } & \multicolumn{1}{c|}{ Level } \\
\hline 1 & Problem-Solving (PROB) & 2.67 & Medium \\
\hline 2 & Global (GLOB) & 2.50 & Medium \\
\hline 3 & Support (SUP) & 2.48 & Low \\
\hline & Overall & 2.55 & Medium \\
\hline
\end{tabular}

As shown in Table 1, the means score indicates that problem-solving and global strategies are used by the students with medium usage. Meanwhile, support strategies are used with low usage. Among the three strategy categories, problem- solving strategies are used most frequently than other two categories. Similarly, Reference [20] revealed that the students were most preferred to use Problem-solving strategy while reading. The next preferred strategy was support strategy, and the least preferred was global strategy.

In the use of each item of reading strategies, 16 of 30 items are reported as moderate usage $(53 \%)$, and 14 of them are reported as low usage $(47 \%)$. No reading strategies are reported as high usage. However, there is a strategy which is used most frequently by the students i.e. "Rereading the text when the text becomes difficult" $(M=3.11)$. This is consistent with [12] whose finding indicated that when the text became difficult, the students preferred to re-read the text, pay close attention to it, and read slowly and carefully to understand it.

\section{B. The Difference of Reading Strategies Used by the Students with Different Levels of Reading Proficiency.}

The students' reading proficiencies were determined from the reading score in First Final Semester Test. Based on the score, the students were grouped into three categories, namely intermediate readers (60-79), poor readers (40-59), and very poor readers $(\leq 39)$. To determine the difference of the students with different levels of reading proficiency in the use of reading strategies, a one-way ANOVA was performed.

TABLE II. TABLE 2. THE DIFFERENCE OF READING STRATEGIES USED BY INTERMEDIATE (I), POOR (P), AND VERY POOR (VP) READERS

\begin{tabular}{|c|c|c|c|c|c|c|}
\hline \multirow{3}{*}{ No. } & \multirow{3}{*}{ Category } & I & $\mathbf{P}$ & VP & \multirow{3}{*}{$\mathbf{F}$} & \multirow{3}{*}{ Sig. } \\
\hline & & $(\mathrm{N}=\mathbf{2 7})$ & $(N=145)$ & $(\mathrm{N}=126)$ & & \\
\hline & & Mean & Mean & Mean & & \\
\hline 1 & GLOB & 2.75 & 2.51 & 2.43 & 2.50 & 0.31 \\
\hline 2 & PROB & 2.98 & 2.72 & 2.53 & 4.10 & 0.10 \\
\hline 3 & SUP & 2.73 & 2.54 & 2.37 & 3.58 & 0.21 \\
\hline
\end{tabular}

The result of the analysis shows that $F_{\text {value was higher than }}$ $\mathrm{F}_{\text {table }}\left(\mathrm{F}_{\text {value }}>\mathrm{F}_{\text {table }}=11,902>3.03\right)$ which indicates that there is difference among the intermediate, poor, and very poor readers in using overall strategies. However, there is no significant difference in the use of each strategy category by the students with different levels of reading proficiency. Furthermore, the mean score of each group shows that more proficient readers used the strategies more frequently than less proficient readers. The finding of this research is supporting the theory of relationship between reading proficiency and the use of reading strategy as proposed by [7] that "Good readers use lots of strategies to help themselves make sense of text.". Furthermore, several studies had also revealed that in using all strategy categories, the more proficient students involved more strategies than less proficient did $[14][15][20][12][13][4]$ 


\section{The Extent to which Reading Strategies Help the Students in Comprehending English Texts}

A multiple regression analysis was conducted to examine how much the use of reading strategies contribute to the students' reading comprehension. The analysis was conducted twice. The first analysis was conducted to find out the correlation of reading strategy use and the students' perception of usefulness. Meanwhile, the second analysis was conducted to find out the correlation between the use of reading strategies and the score of students' reading comprehension. The result of first analysis shows that the overall use of reading strategies is significantly related to the students' reading comprehension. The value of square of correlation was 0.597 , which indicates that the use of reading strategies help the students to comprehend English text approximately $59.7 \%$. Unlike the first analysis, the second multiple regression analysis between reading strategy use and the students' score of reading comprehension shows a very different result from the first analysis. The result of the analysis shows that the use of reading strategies contributes to students' reading comprehension approximately $18.4 \%$. From both analysis, it could be concluded that the use of reading strategies has moderate but significant correlation with the students' reading comprehension. In other words, the use of reading strategies moderately help the students in comprehending English texts. This finding is in line with other findings $[20 ; 12 ; 13]$ which revealed that the use of reading strategies was moderately correlated with students' reading comprehension. However, this finding is different from [4] who found that there was no significant correlation between reading strategies use and reading comprehension ability.

Looking at the extents of the reading strategies use in helping the students in comprehending English texts which are different from the first and the second analysis (i.e.: $59.7 \%$ and $18.4 \%$ ), it can be assumed that the students believe that the use of reading strategies could help them increase their reading comprehension. However, in fact, reading strategies that they use in completing the test do not give much contribution to their reading comprehension score since they may not use the appropriate strategies while working with the texts. Therefore, teachers should train the students to use the strategies appropriately so that the strategies perceived as helpful will be really beneficial for them and they could achieve better reading comprehension.

\section{CONCLUSION}

In conclusion, reading strategies used by senior high school students are similar with the ones used by university students. The more proficient readers apply reading strategies which are different from the ones applied by less proficient readers. Moreover, the use of reading strategies is found helpful for the students in comprehending English texts. More specifically, the result of the analysis demonstrates that the students use Problem- solving strategy most frequently than global strategies and support strategies ( $\mathrm{PROB}>$ GLOB $>$ SUP). Strategy which is most frequently used by the students is "Rereading when text becomes difficult", and strategy which is most rarely used is "Reading aloud when text becomes difficult". The study also reveals that there is significant difference among intermediate, poor, and very poor readers in using overall reading strategies. Intermediate readers involve more strategies than poor readers and very poor readers when they comprehend English texts. Furthermore, two regression analyses were conducted to find out the extent of reading strategy use in helping the students in comprehending English texts. The result of the analysis shows that the use of reading strategies is moderately correlated with the students' reading comprehension. Regarding the findings and the limitations of this research, there are several suggestions for further researchers. First, further researchers need to enhance the data collection technique by doing observation or interview to find out the actual use of reading strategies in comprehending English texts. Second, the participant of further research should be from several senior high schools in Indonesia so that they could be more representative. Third, since this research revealed that there was relationship between reading strategy use and students' reading comprehension, it is suggested for further researcher to give reading strategy training for the participants to find out the real effect of reading strategy use toward the student's reading comprehension.

\section{REFERENCES}

[1] T. Hudson, Teaching Second Language Reading. New York: Oxford University Press, 2007.

[2] N. Munsakorn, "Awareness of Reading Strategies among EFL Learners at Bangkok University,” Int. J. Soc. Behav. Educ. Econ. Bus. Ind. Eng., vol. 6, no. 4, 2012.

[3] A. Poole, "Gender Differences in Reading Strategy Use Among ESL College Students,” J. Coll. Read. Learn., vol. 36, no. 14, 2005.

[4] Y. H. Park, "Korean EFL College Students' Reading Strategy Use to Comprehend Authentic Expository/Technical Texts in English," 2010.

[5] W. Grabe and F. . Stoller, Teaching and Researching Reading. New York: Routledge, 2011.

[6] J. . Alderson, Assessing Reading. Cambridge: Cambridge University Press, 2000.

[7] C. Tovani, I Read It but I Don't Get It: Comprehension Strategies for Adolescent Readers. Colorado: Stenhouse Publisher, 2000.

[8] N. . Anderson, "Individual Differences in Strategy Use in Second Language Reading and Testing," Mod. Lang. J., vol. 13, 1991.

[9] K. Mokhtary and R. Sheorey, "Differences in the Metacognitive Awareness of Reading Strategies among Native and Non-native readers," vol. 19, 2001.

[10] D. S. McNamara, Reading Comprehension Strategies: Theories, Intervensions and Technologies. New York: Lawrence Erlbaum Associates, 2007.

[11] M. L. Lee, "A Study of the Selection of Reading Strategies among Genders by EFL College Students,” Procedia - Soc. Behav. Sci., vol. 10, 2012.

[12] J. M. Magogwe, "Metacognitive awareness of reading strategies of University of Botswana English as Second Language students of different academic reading proficiencies," Read. Writ., vol. 8, 2013.

[13] K. H. N. . Page, "Investigating Metacognitive Awareness and Reading Strategy Use of EFL Korean University Students," Read. Psychol., vol. 28, 2014.

[14] M. N. Abdelmalek, "Research on Reading Strategies: Results from High and Low Readers, Native and Non-Native English Speakers, and Male and Female Students," Los Angeles, 2015.

[15] H. Kim, "The Relationships Between Korean University Students' Reading Attitude, Reading Strategy Use, and Reading Proficiency," Read. Psychol., vol. 35, 2016. 
[16] J. R. Fraenkel, N. E. Wallen, and H. H. Hyun, How to Design and Evaluate Research in Education. New York: The McGraw-Hill Companies, 2012.

[17] A. Bhattacherjee, Social Science Research: Principles, Methods, and Practices. Florida: Scholar Commons, 2012.

[18] L. Cohen, L. Manion, and K. Morrison, Research Method in Education. New York: Routledge, 2007.

[19] A. C. Graesser, An Introduction to Strategic Reading Comprehension Reading Comprehension Strategies: Theories, Intervensions, and Technologies. New York: Lawrence Erlbaum Assossiates, 2007.
[20] P. Madhumatti and A. Ghosh, "Awareness of Reading Strategy Use of Indian ESL Students and the Relationship with Reading Comprehension Achievement English Language Teaching," vol. 5, no. 10, 2012.

[21] J. Larson-Hall, A Guide to Doing Statistics in Second Language Research Using SPSS. New York: Routledge, 2010.

[22] A. Mackey and S. M. Gass, Second Language Research: Methodology and Design. New Jersey: Lawrence Erlbaum Associates, 2005.

[23] K. Mokhtary and R. Sheorey, "Measuring ESL Studers' Awareness of Reading Strategies,” J. Dev. Educ., vol. 25, no. 6, 2002.

[24] L. L. Nathans, F. L. Oswald, and K. Nimon, "Interpreting Multiple Linear Regression: A Guidebook of Variable Importance. Practical Assessment, Research and Evaluation," vol. 17, no. 19, 2012. 